\title{
Promoting pride in practice
}

$\mathrm{C}$ an posters improve health care? Indeed they can, at least for patients who don't always feel welcome in doctors' offices, says Dennis Baldwin, a project manager for The Lesbian and Gay Foundation, a charity based in Manchester, United Kingdom.

"Something as small as having a poster supporting LGB [lesbian, gay, bisexual] health services can send a message to LGB patients that they are in a safe environment," says Baldwin. "Small visual cues can help."

Yet when the foundation ran a campaign two years ago to encourage GP surgeries (a UK term referring to facilities where general practitioners provide primary care) to put up posters with a helpline number for LGB patients, it was met with a surprising amount of resistance and, in some cases, hostility. That experience led to the creation of the foundation's current campaign, Pride in Practice, a tool kit to help health providers learn how to use inclusive language and imagery, train staff on LGB issues and monitor how people of various sexual orientations are accessing health services.

"We couldn't assess how many people from LGBT [lesbian, gay, bisexual, transgender] backgrounds were registering with different GPs," says Shahnaz Ali, director of equality, inclusion and human rights at NHS (National Health Service) North West, a partner in the Pride in Practice initiative. "We commissioned this project to try to get some of that intelligence data and also to work with these practices to be LGBT-friendly."

According to The Lesbian and Gay Foundation, research has shown that many in the LGBT community avoid accessing public health services for fear of homophobia, while a large portion of lesbian and bisexual women report inappropriate comments and other negative experiences in health care settings, and people are often reluctant to disclose their sexual orientation to mainstream mental health care providers (www.lgf.org.uk/prideinpractice).

"Mental health problems are the biggest issues," says Baldwin.
Though services tailored to the LGBT community tend to focus on sexual health, mental health is indeed an area of dire need. One study conducted in England and Wales found that, compared to heterosexuals, gay men and lesbians experience higher levels of psychological distress and were more likely to harm themselves and abuse recreational drugs ( $B r J P s y-$ chiatry 2003;183:552-8). Another found that $31 \%$ of 1285 gay, lesbian and bisexual respondents had attempted suicide due to factors including discrimination and bullying (Br J Psychiatry 2004;185:479-85). A more recent survey confirmed earlier findings that nonheterosexuals experience more mental health problems and that perceived discrimination only exacerbates these problems (Br J Psychiatry 2011; 198:143-8).

Baldwin hopes Pride in Practice which will award gold, silver or bronze awards to GP surgeries depending on the levels of service they offer to LGB patients - will create environments where people at high risk of mental

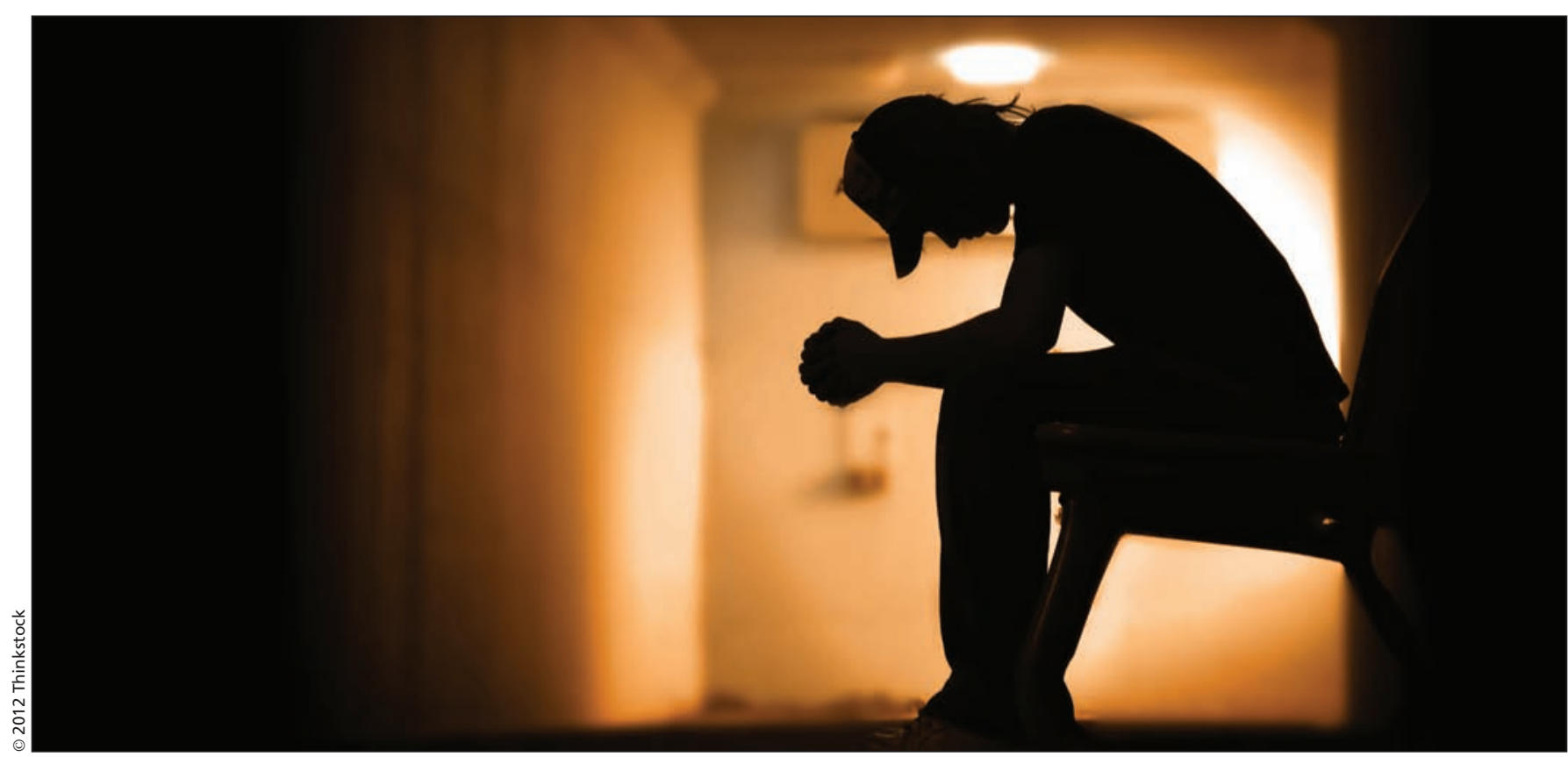

Members of the LGBT (lesbian, gay, bisexual, transgender) community are more likely than heterosexuals to experience mental health problems, abuse drugs and intentionally harm themselves. 
health problems feel comfortable revealing and discussing their sexuality.

"We will see more early diagnoses and, hopefully, early interventions," says Baldwin.

Of course, the UK isn't the only place where nonheterosexual patients and doctors - have negative experiences in the health care system. In early July, 70 Canadian physicians joined a gay-pride parade in Toronto, Ontario, to promote better health care for the LGBT community and improved working conditions for nonheterosexual doctors (www.cmaj.ca/lookup/doi/10.1503/cmaj .109-4252). Canadian patients have reported feeling excluded, isolated and fearful due to their sexuality, and nonheterosexual physicians have experienced homophobia in the workplace (J Child Adolesc Psychiatr Nurs 2010; 23:23-8). Doctors in the march called for greater education for medical students on LGBT health issues, beyond those, such as increased risk for HIV, that are already commonly taught.

A good first step, according to Baldwin, would be for doctors to keep their minds open about the sexual orientation of their patients. "If the assumption from the get go is that we are heterosexual, it can be quite difficult to broach the subject," says Baldwin. "If you are already concerned about your health, and you also fear of repercussions you might face, it adds to the pressure."

The Pride in Practice campaign will also encourage health providers to "monitor" the sexual orientation of patients, a valuable practice that is woefully lacking in the UK, according to Ali. In fact, she says, health information about two groups - people with disabilities and members of the LGBT community - represent the largest evidence gaps about how people access health services in the UK. "The NHS is here to provide universal services for everyone in the population," she says. "How do we make sure services are appropriate and accessible if you don't have the right data?"
Asking people to disclose their sexual orientation, however, can be a sensitive task, even if the purpose is to ensure equality. Patients may fear the information will be handled carelessly or used in a way that will affect them negatively. To address this issue, NHS North West and the Lesbian and Gay Foundation released a workbook on how to properly implement sexual orientation monitoring (http://ripassetseu .s3.amazonaws.com/www.lgf.org.uk /_files/documents/nov_11/FENT_13215 30573_Sexual-orientation-monitoring -.pdf).

"If you are responsible for data collection, remember that the information you're receiving is highly personal, and be honest about people's response to that," states the workbook. "It's essential that you have a clear and comprehensive confidentiality policy that you stick to and communicate clearly to staff and service users who are being asked their sexual orientation."

A case study in the workbook describes how one organization electronically records sexual orientation information using a coding system. Only staff involved in analyzing the data are able to read it, which is made clear to people on monitoring forms.

Some people question, though, if individual health providers can truly promise that sensitive information such as sexual orientation will remain secure. When medical data makes its way into an electronic system, for instance, it generally ends up in a giant repository that a surprisingly large number of people can access, according to Michael Vonn, policy director for the British Columbia Civil Liberties Association.

"Doctors should be obliged to inform patients that when information goes into an electronic health record, a doctor cannot guarantee confidentiality or [who] will access that information," says Vonn. "We have a powerful incentive to keep this information confidential but we have to grapple with the fact that the information system architec- tures we are building makes this increasingly difficult."

In Canada, there doesn't appear to be any laws preventing health providers from asking patients their sexual orientation, though there is a "mish mash of privacy legislation" across the country, says David Fraser, a privacy lawyer who runs a popular website on Canadian privacy legislation (www.privacy lawyer.ca).

Disclosing this type of "secondary information" could not be a condition of receiving medical care, though, and providers would have to identity the purpose of collecting it and obtain informed consent. That could be more complicated than it appears.

"So much depends on how the question is asked to the individual. How clearly it will be communicated to the person without being coercive," says Fraser. "As soon as you collect that sort of information, and this is particularly sensitive, it needs to be protected and safeguards have to be appropriate to the sensitivity of the information. It may well be that institutions would say: 'Legally, we can collect this, but we don't want to accept responsibility for this'."

Still, despite the complications involved, there seems to be a big push to obtain sexual orientation information about patients in the UK. And implementing the monitoring is no easy task. It requires training staff, educating patients about how collecting this information will improve their health services and convincing leaders of health organizations that the data not only benefit the LGBT community but also their practices.

"We have to change the mindset of the organization," says Ali. "This isn't just about doing it for the good of the LGBT population. Do it because you can be more efficient and provide much better services, tailored to local populations. Because that is, ultimately, what we should have." - Roger Collier, CMAJ

CMAJ 2012. DOI:10.1503/cmaj.109-4296 